\title{
PEMBUATAN DAN KARAKTERISASI KARBON AKTIF DARI SERBUK ARANG KAYU ULIN DENGAN AKTIVASI KOH DAN APLIKASINYA UNTUK MENURUNKAN KROM PADA LIMBAH CAIR SASIRANGAN \\ DEVELOPMENT AND CHARACTERIZATION OF ACTIVATED CARBON POWDER CHARCOAL WOOD ULIN ACTIVATION WITH KOH AND APPLICATION TO REDUCE WASTE CHROME SASIRANGAN
}

\author{
Asmarika Wibawati, Mahmud, Chairul Abdi \\ Program Studi Teknik Lingkungan, Fakultas Teknik,Univeritas Lambung Mangkurat, \\ Jl. Jend A. Yani, Km 36, Banjarbaru, 70714, Kalimantan Selatan, Indonesia. \\ Email: Asmarikaw11@gmail.com
}

\begin{abstract}
ABSTRAK
Krom merupakan salah satu jenis logam berat yang memiliki toksisitas tinggi dan melebihi ambang batas sehingga dapat menurunkan kualitas lingkungan di perairan. Salah satu cara mengurangi kadar krom dalam limbah cair sasirangan ialah dengan adsorpsi menggunakan arang aktif sebagai absorben. Serbuk gergaji kayu ulin adalah salah satu limbah yang banyak tidak dimanfaatkan dan dapat mengganggu estetika lingkungan. Sehingga memiliki potensi sebagai bahan baku dalam pembuatan karbon aktif. Dalam penelitian ini dilakukan adsorpsi terhadap logam berat $\mathrm{Cr}$ menggunakan karbon aktif serbuk kayu ulin berukuran 80-100 mesh sebagai karbon aktif. Penelitian bertujuan untuk menyelidiki pengaruh variasi waktu dan molaritas terbaik terhadap besarnya efesiensi absorpsi. Dari hasil penelitian menunjukkan bahwa waktu dan molaritas yang paling efektif adalah waktu perendaman 24 jam dengan molaritas terbaik adalah 3 M. Sedangkan untuk penurunan Cr pada limbah cair sasirangan menghasilkan efesiensi adsorpsi sebesar $65 \%$.
\end{abstract}

Kata kunci: Serbuk arang kayu ulin, limbah cair sasirangan, $\mathrm{KOH}, \mathrm{Cr}$

\section{ABSTRACT}

Krom is one kind of heavy metal that has a high toxicity and exceeding the threshold that can degrade the quality of the environment in its waters. One way to reduce the levels of chromium in the wastewater sasirangan is by adsorption using activated carbon as an absorbent. Sawdust ironwood is a lot of waste that is not used and can interfere with the aesthetics of the environment. So it has potential as a raw material in the manufacture of activated carbon. In this research $\mathrm{Cr}$ adsorption against using activated carbon powder ironwood 80-100 mesh size as activated carbon. The study aims to investigate the influence of variations in the time and the best molarity on the size of the absorption efficiency. The results showed that time and the most effective molarity is 24 hours soaking time with the best molarity was $3 \mathrm{M}$. As for the reduction of $\mathrm{Cr}$ in wastewater sasirangan produce adsorption efficiency by $65 \%$.

Keywords: Powder, ironwood charcoal liquid waste sasirangan, $\mathrm{KOH}, \mathrm{Cr}$ 


\section{PENDAHULUAN}

Industri sasirangan yang berada didaerah Kalimantan Selatan mengalami perkembangan yang sangat pesat. Turut menyumbang kesejahteraan masyarakat lokal, tetapi dengan banyaknya industry sasirangan turut menyumbang permasalahan lingkungan, khususnya pencemaran yang diakibatkan dari limbah sasirangan itu sendiri. Limbah cair sasirangan yang melebih baku mutu diatur oleh pergub Kalsel Nomer 36 tahun 2008 tentang baku mutu limbah cair (BMLC) Bagi kegiatan industri, rumah sakit, dan pertambangan. Limbah cair sasirangan banyak sekali mengandung logam berat Cr. Hasil dari penelitian Santoso (2014) Mengatakan bahwa limbah cair sasirangan banyak mengandung Cr.

Logam berat yang sukar diuraikan dan sangat berbahaya bagi kesehatan manusia salah satunya adalah logam Cr. Logam Cr sering digunakkan sebagai bahan untuk pelapis logam, pembuatan cat dan pewarna tekstil. Kadar maksimum pencemar $\mathrm{Cr}$ pada perairan sebesar 1,0 mg/L. Didaerah Banjarmasin sendiri, setelah dilakukan analisa, ternyata kandungan logam $\mathrm{Cr}$ cukup tinggi jika dibandingkan dengan baku mutu, yakni sebesar 2,274 mg/L.

Serbuk kayu ulin (Eusideroxylon Zwageri Teijsm \& Binn) sebagai bahan baku untuk pembuatan arang aktif. Serbuk kayu ulin yang selama ini dibiarkan begitu saja menjadi limbah dan merusak keindahan lingkungan sekitar, padahal serbuk kayu ulin dapat dimanfaatkan untuk keperluan lainnya, salah satu alternatifnya yaitu bisa digunakan untuk pembuatan karbon aktif sebagai penyerap untuk menurunkan krom. Dalam menentukan kualitas arang aktif dapat dilihat dari luas permukaannya. Semakin luar permukaan porinya arang, maka semakin tinggi kemampuan arang aktif dalam mengadsorpsi zat pencemar. (Murniati, 2014)

Ciri-ciri kayu ulin yang mempunyai dinding sel dan serat yang sangat tebat serta sel yang dipenuhi ekstratif. Kayu ulin memiliki selulosa $51 \%$, lignin $28,9 \%$, pentosin $12,7 \%$ dan berat jenis yang tinggi $(1,04)$ (Jauhari dkk, 2007). Pemanfaatan kayu ulin sendiri telah dilakukan oleh Setiawan (2014), sebagai karbon aktif untuk menurunkan BOA pada air sungai. Hasil penelitian tersebut menunjukkan bahwa kayu ulin yang dihasilkan dengan aktivasi kimia dapat meningkatkan luas permukaan spesifik, dari $56 \mathrm{~m}^{2} / \mathrm{g}$ menjadi $171,8 \mathrm{~m}^{2} / \mathrm{g}$ dan dapat menyisihkan BOA sebesar 86,09\%. Sehingga karbon aktif kayu ulin ini sangat efektif.

Penelitian ini menggunakan aktivasi kimia dengan menggunakan $\mathrm{KOH}$. Berdasarkan penelitian sebelumnya Salamah (2008) KOH adalah salah satu aktivator yang mempunyai aktivasi baik, selain mudah didapat, dan harganya juga ekonomis. Penggunaan bahan aktivasi yang baik diharapkan dapat menghasilkan daya adsorpsi besar pada pemanfaatan serbuk kayu ulin menjadi karbon aktif.

Penelitian ini bertujuan untuk menentukan karakteristik adsorben arang kayu ulin setelah diaktivasi secara kimia menggunakan $\mathrm{KOH}$. Kemudian menyelidiki kemampuan adsorben arang aktif kayu ulin dalam menurukan krom pada limbah cair sasirangan.

\section{METODE PENELITIAN}

\section{Bahan dan Peralatan Penelitian}

Bahan-bahan yang digunakan untuk penelitian ini diantaranya: Serbuk kayu ulin yang didapat dari desa Karang Jawa, Pelaihari, Kab Tanah Laut. Limbah cair sasirangan dari kampung sasirangan Banjarmasin, Kalimantan Selatan. Akuades, larutan KOH, NaCL dan HCL (Merck). Alat yang akan digunakan pada penelitian kali ini diantaranya; Oven untuk menghilangkan kadar air pada adsorben,pH meter untuk mengukur $\mathrm{pH}$, Vakum pump, neraca analitik, ayakan tanah ukuran 80-100 mesh, kertas saring, dan Inductively Coupled Plasma (ICP) sebagai alat mengukur konsentrasi Cr. 


\section{Prosedur Penelitian}

\section{Uji Karakteristik Serbuk kayu ulin}

a. Analisis Kadar Air

Sampel ditimbang sebanyak 5 gram dan kemudian sampel dimasukan kedalam oven dengan suhu $105^{\circ}$ C.menghitung kadar air dapat ditentukan dengan persamaan;

Kadar Air $=\frac{(W a-W b)}{W a} \times 100$

Dimana;

Wa : Berat sampel awal (mg)

$\mathrm{Wb}$ : Berat sampel akhir (mg) (Edema dkk., 2012)

b. Berat Jenis

Sampel kayu ditimbang berat basahnya dan diukur volumenya, kemudian dikeringkan dalam oven dengan suhu $\pm 105^{\circ} \mathrm{C}$ selama 24 jam. Setelah itu barulah ditimbang berat keringnya.

Berat jenis kayu dapat dihitung dengan rumus sebagai berikut;

Berat Jenis Kayu $=\frac{\text { Massa kering kayu }(\mathrm{gr})}{\text { Volume kering kayu }(\mathrm{cm})}$

(Ginoga., 1974 dalam kusuma, 2009)

\section{Preparasi Karbon aktif arang Kayu Ulin}

Serbuk kayu ulin dimasukkan kedalam wadah tertutup dan tidak mudah terbakar. Bagian atas wadah dilubangi agar saat pembakaran wadah tidak penyok. Serbuk kayu ulin yang telah dibakar kemudian di masukkan kedalam alat Furnace untuk pemantapan proses karbonisasi dengan suhu $400^{\circ} \mathrm{C}$.

Serbuk kayu ulin dihancurkan dan diayak untuk memperoleh ukuran arang serbuk kayu ulin 80-100 mesh yang nantinya akan mengalami aktivasi kimia menggunakan $\mathrm{KOH}$ untuk dijadikan karbon aktif serbuk kayu ulin. (Setiawan, 2014)

\section{Aktivasi Arang Aktif}

Proses aktivasi arang aktif serbuk kayu ulin dilakuakn secara kimia dengan menggunakan aktivator $\mathrm{KOH}$ untuk memperbesar luas permukaan. Untuk proses aktivasi kimia ini digunakan $\mathrm{KOH}$ dengan berbagai variasi konsentarsi yaitu 1 M, 1,5 M, 2 M, 2,5 M, 3 M dan 3,5 M. Setelah didapat KOH dengan molaritas yang diinginkan selanjutnya arang aktif kyu ulin masing masing sebanyak $25 \mathrm{gr}$ dimasukkan kedalam erlenmeyer $250 \mathrm{ml}$ dan dicampurkan dengan $\mathrm{KOH}$ berbagai molaritas, dan direndam serta dikocok agar larutan tercampur. Setelah itu didiamkan dengan waktu variasi 12 jam, 18 jam dan 24 jam untuk proses aktivasi agar melarutkan mineral organik pada arang serbuk kayu ulin sehingga menyebabkan pori-pori arang aktif menjadi terbuka lebih besar dari sebelumnya. Arang yang telah teraktivasi selanjutnya dicuci degan akuades untuk menghilangkan sisa $\mathrm{KOH}$ yang masih terdapat dalam karbon aktif. Selanjutnya karbon aktif kayu ulin dikeringkan dalam oven dengan suhu $110^{\circ} \mathrm{C}$. (Setiawan, 2014)

\section{Karakterisasi Arang Kayu Ulin}

Proses karakterisasi diawali dengan sampel karbon aktif arang kayu ulin sebanyak 0,5 gram diasamkan dengan $\mathrm{HCl}$ 0,1 M sampai mencapai $\mathrm{pH} 3-3,5$. Kemudian ditambahkan 10,0 gram $\mathrm{NaCl}$ dan ditambahkan pula air suling sehingga mencapai volume $50 \mathrm{~mL}$. Larutan ini kemudian dititrasi dengan $0,1 \mathrm{M} \mathrm{NaOH}$, sampai mencapai $\mathrm{pH} 4,0$; kemudian diaktifkan lagi penambahan $0,1 \mathrm{M} \mathrm{NaOH}$ 
sampai mencapai harga $\mathrm{pH} 9,0$. Volume yang diperlukan untuk menaikan $\mathrm{pH}$ 4,0 sampai 9,0 dicatat dan selanjutnya luas permukaan spesifik dapat di hitung dengan persamaan :

$S=\left(\mathrm{m}^{2} / \mathrm{g}\right)=32 V-25$

Dimana :

$S \quad=$ Luas permukaan $\left(\mathrm{m}^{2} / \mathrm{g}\right)$

$V \quad=$ Volume titrasi $(\mathrm{mL})$

Setelah di dapatkan data, selanjutnya di lakukan analisis berdasarkan data hasil uji untuk proses pengkarakteristikan. (Pradista, 2016)

\section{Uji Efektifitas}

Arang aktif serbuk kayu ulin yang sudah dijadikan karbon aktif akan dilakukan uji efektifitas dengan FTIR. Sampel karbon aktif sebelum dan sesudah aktivasi dikirim ke laboratorium Sentral Universitas Negeri Malang untuk mengetahui gugus fungsional yang terkandung di dalam karbon aktif (FTIR).

\section{Perlakuan Terhadap Limbah Cair Sasirangan}

Karbon aktif arang aktif kayu ulin yang telah siap akan dicampurkan kedalam limbah cair sasirangan untuk mendapatkan $\mathrm{pH}$ terbaik yaitu pada $\mathrm{pH} 3$, dan dosis optimum 2 g dengan waktu kontak 4 jam dan kecepatan pengadukan $180 \mathrm{rpm}$. Sehingga dihasilkan karbon aktif arang aktif kayu ulin yang mampu menurunkan $\mathrm{Cr}$ secara optimum pada limbah cair sasirangan. Proses adsorpsi yang dilakukan yaitu secara batch. (Lestari, 2016).

Kandungan $\mathrm{Cr}$ dalam limbah cair sasirangan diukur menggunakan ICP. Hasil pengukuran dilakukan perhitungan kapasitas adsorpsi (Qe) $\mathrm{Cr}$ dan persentase penurunan menggunakan persamaan:

$Q e=\frac{C i-C e}{w} x V$

$\%$ Penurunan $=\frac{\text { Kadar Awal }- \text { Kadar Akhir }}{\text { Kadar Awal }} \times 100 \%$

Dimana:

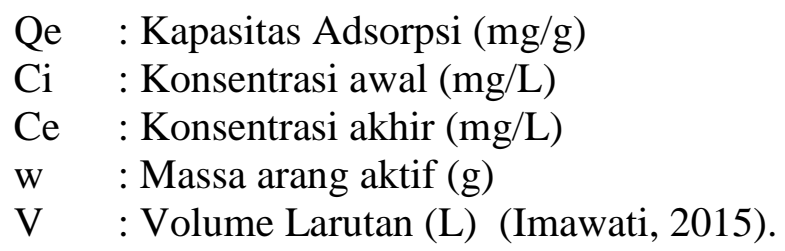

\section{HASIL DAN PEMBAHASAN}

Limbah serbuk kayu ulin banyak menimbulkan masalah dalam penanganannya yang selama ini dibiarkan membusuk dan ditumpuk begitu saja, semua itu berdampak negatif dan menimbulkan masalah baru bagi lingkungan sehingga penanggulangannya perlu difikirkan. Salah satunya serbuk kayu ulin dapat dimanfaatkan menjadi karbon aktif yang dapat menurunkan krom pada limbah cair sasirangan.

Dibawah ini merupakan hasil dari kadar air dan berat jenis serbuk kayu ulin didapatkan hasil sebagai berikut; 
Tabel 1 Hasil Karakteristik kadar air dan berat jenis

\begin{tabular}{ccc}
\hline No & Karakteristik & Jumlah Kandungan \\
\hline 1 & Kadar Air & $17,5 \%$ \\
2 & Berat Jenis & 110 \\
\hline
\end{tabular}

Berdasarkan perhitungan awal seperti yang terdapat pada table 4.1 diatas bahwa kadar air serbuk kayu ulin sangat berpengaruh dalam pembuatan karbon aktif dan juga kualitas karbon aktif. Tingginya kadar air pada serbuk gergaji kayu ulin disebabkan karena pada serbuk gergajian kayu memiliki ukuran partikel yang lebih besar dan jumlah pori-pori yang lebih banyak, selain itu juga serbuk gergaji kayu masih banyak mengandung komponen-komponen kimia seperti selulosa, lignin dan hemiselulosa. Kadar air pada serbuk gergaji kayu ulin ini sebesar 17,5\%.

Berat jenis serbuk kayu ulin dapat dihitung menggunakan persamaan berat kering dan berat basah. Sehingga dapat diketahui berat jenis serbuk kayu ulin tersebut. Berat jenis serbuk kayu ulin tersebut sebesar 110.

Serbuk kayu ulin yang digunakan dalam penelitian ini berasal dari Desa Karang jawa, Kab Tanah Laut. Serbuk kayu ulin memiliki tekstur padat dapat dilihat pada Gambar 1 dibawah ini;

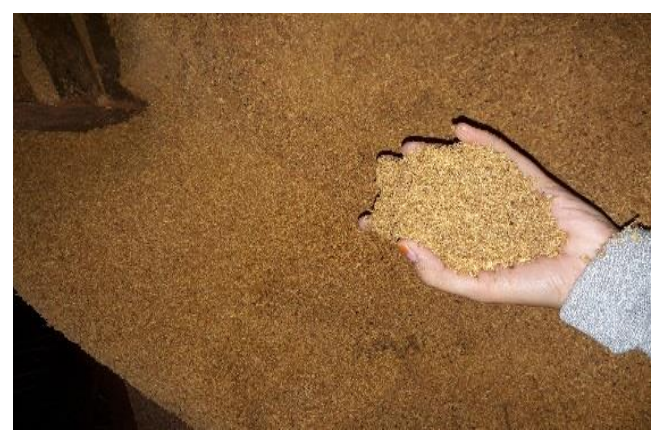

Gambar 1 Serbuk kayu ulin

Dari Gambar 1 terlihat gambaran kualitas fisik serbuk kayu ulin yang berwarna coklat gelap. Ini dikarenakan serbuk gergaji kayu ulin masih memiliki kadar air yang cukup tinggi dan cenderung lembab. Sehingga warna serbuk kayu ulin cenderung berwarna coklat gelap. Sedangkan dari teksturnya serbuk kayu ulin memiliki tekstur yang agak sedikit kasar dan serutan yang cenderung kecil.

\section{Karakteristik Limbah Cair Sasirangan}

Kandungan krom pada limbah sasirangan di Banjarmasin mencapai angka 2,274 mg/L telah melebihi baku mutu menurut peraturan Gubernur Kalimantan Selatan No. 36 tahun 2008. Berdasarkan penelitian safriansyah (2014), karakteristik limbah cair sasirangan dapat dilihat pada Tabel 2.

Tingginya kandungan $\mathrm{Cr}$ pada limbah sasirangan disebabkan karena adanya gugus kromofor dan auksokrom yang cukup tinggi dalam pewarnaan. Gugus ini berfungsi sebagai pengikat antar warna dan serat kain yang membuat warna lebih melekat sehingga mengurangi kelunturan warna pada kain pada saat proses pencucian. Sedangkan kadar pH, TDS, TSS, BOD, dan COD yang tinggi dikarenakan air sebagai pelarut menggunakan air sumur. (Safriansyah., 2014) 
Tabel 2. Karakteristik limbah cair sasirangan

\begin{tabular}{llcc}
\hline No. Parameter & Satuan & Jumlah Terkandungan & $\begin{array}{c}\text { Pergub Kalsel } \\
\text { No. 36 Tahun 2003 }\end{array}$ \\
\hline 1. Krom (Cr) & ppm & 18,12 & 1,0 \\
2. $\mathrm{pH}$ & & 9,50 & $3-9$ \\
3. TDS & ppt & 17,40 & \\
4. TSS & ppm & 578 & 50 \\
5. BOD & ppm & 2.400 & 60 \\
6. COD & ppm & $3.247,4$ & 150 \\
\hline
\end{tabular}

\section{Pengaruh Konsentrasi KOH dan waktu Perendaman Terhadap Luas Permukaan Karbon Aktif dengan Uji Searsc pada Serbuk Kayu Ulin}

Konsentrasi $\mathrm{KOH}$ sangat penting untuk menentukan luas permukaan karbon aktif. Semakin luas permukaan karbon aktif, maka semakin besar luas permukaan karbon aktif. Hasil pengaruh konsentrasi $\mathrm{KOH}$ dan waktu perendaman terhadap luas permukaan karbon aktif kayu ulin dapat dilihat pada Gambar 2.

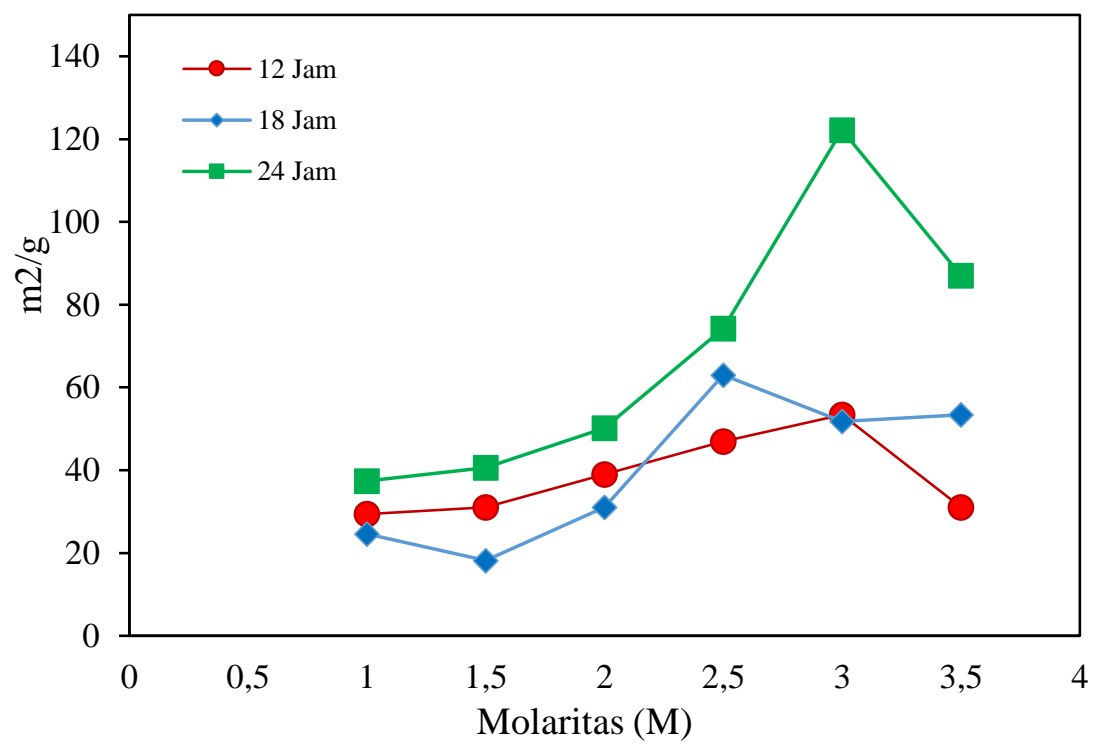

Gambar 2. Hubungan antara konsentrasi $\mathrm{KOH}$ terhadap luas permukaan karbon aktif kayu ulin

Konsentrasi $\mathrm{KOH}$ mempengaruhi peningkatan luas permukaan karbon aktif serbuk kayu ulin. Pada waktu perendaman 12 jam menunjukan pada konsentrasi $3 \mathrm{M}$ luas permukaan karbon aktif serbuk kayu ulin menunjukan luas permukaan yang tertinggi. Sedangkan pada waktu perendaman 18 jam menunjukan pada konsentrasi 2,5 M luas permukaan karbon aktif serbuk kayu ulin menunjukan luas permukaan yang tertinggi. Dan pada waktu perendaman 24 jam menunjukkan pada konsentrasi $3 \mathrm{M}$ luas permukaan karbon aktif serbuk kayu ulin menunjukan yang paling tinggi diantara waktu perendaman 12 jam dan 18 jam. Pada molaritas 3,5 M dengan waktu perendaman 24 jam menunjukan penurunan pada luas permukaannya. Ini dikarenakan dengan konsentrasi tinggi dan waktu perendaman yang terlalu lama dapat menyebabkan terjadinya reaksi yang terlalu besar, sehingga dapat merusak setruktur pori dan akhirnya luas permukaan yang dihasilkannya pun rendah. 


\section{Karakteristik Gugus Fungsi Adsorben Kayu Ulin}

Pengujian karakteristik kimia dengan menggunakan metode FTIR (Fourier Transform Infrared) untuk mengetahui gugus fungsi atau ikatan-ikatan molekul yang ada pada sampel arang aktif kayu ulin sebelum dan sesudah aktivasi. Spektra inframerah yang dihasilkan pada karbon aktif sebelum dan sesudah dapat dilihat pada Gambar 3, Sebagai berikut;

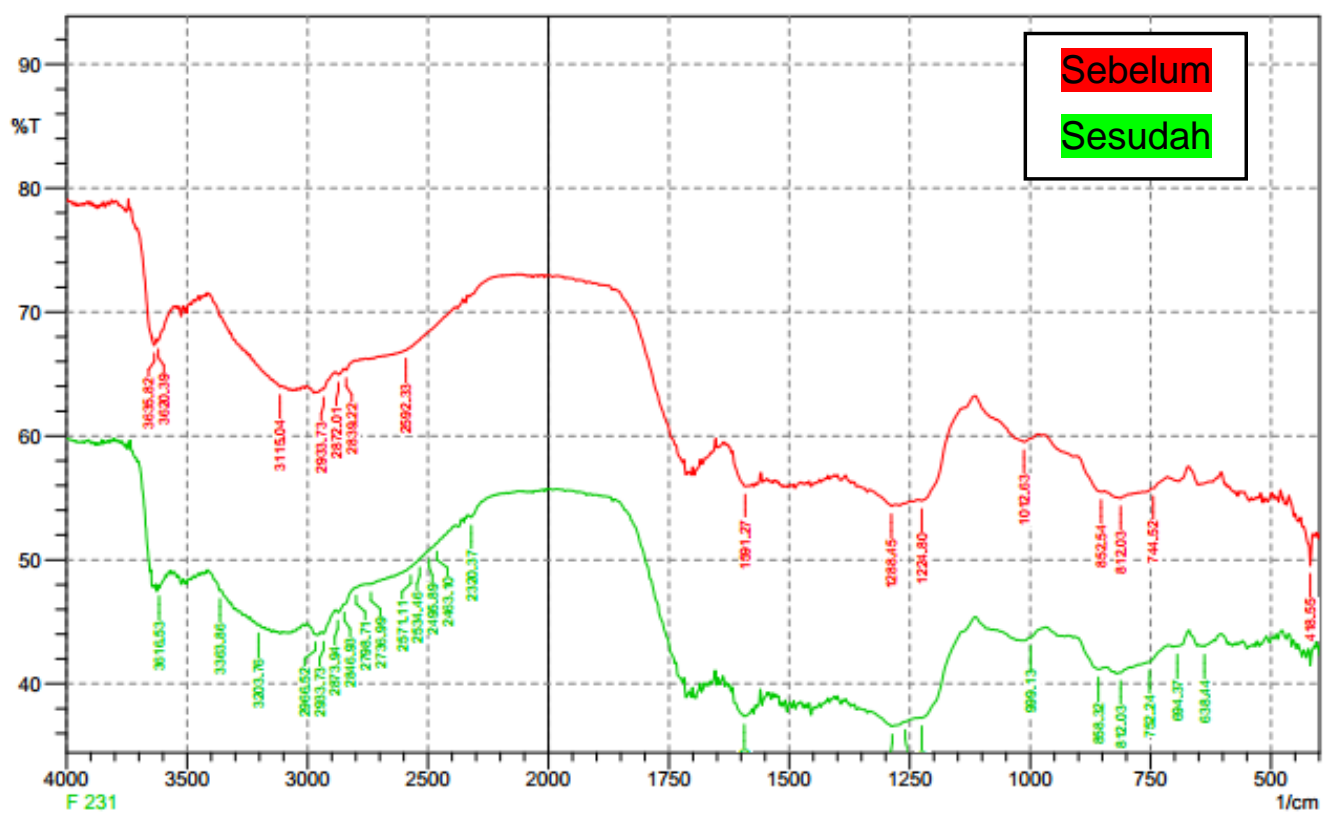

Gambar 3 Hasil Pengujian FTIR Arang Aktif Kayu Ulin

Dari hasil Pengujian FTIR sebelum aktivasi dan setelah aktivasi menunjukan beberapa puncak serapan yang karakteristik. Analisis FTIR arang aktif kayu ulin sebelum aktivasi menggambarkan serapan yang melebar dengan intensitas cenderung kuat muncul puncak pada angka gelombang 3500$3650 \mathrm{~cm}^{-1}$ yang kemungkinan menunjukkan adanya gugus $\mathrm{O}-\mathrm{H}$ asam karboksilat monomer yang biasanya muncul pada angka gelombang tersebut. Munculnya puncak pada angka gelombang 2850$2970 \mathrm{~cm}^{-1}$ yang kemungkinan menunjukkan adanya gugus C-H Alkana yang biasanya muncul pada angka gelombang 2850-2970 dan 1340-1470 $\mathrm{cm}^{-1}$. Munculnya puncak pada angka gelombang 1690$1760 \mathrm{~cm}^{-1}$ yang kemungkinan menunjukkan adanya gugus $\mathrm{C}=\mathrm{O}$ Aldehid/ keton/ asam karboksilat/ ester yang biasanya muncul pada angka gelombang tersebut. Munculnya puncak pada angka gelombang $1500-1600 \mathrm{~cm}^{-1}$ yang kemungkinan menunjukkan adanya gugus $\mathrm{C}=\mathrm{C}$ cincin aromatik yang biasanya muncul pada angka gelombang tersebut. Munculnya puncak pada angka gelombang $1180-1360 \mathrm{~cm}^{-1}$ yang kemungkinan menunjukkan adanya gugus C-N Amina/ amida yang biasanya muncul pada gelombang tersebut. Menurut Prasetyo dan harun (2013), gugus fungsi yang sesuai dengan struktur karbon aktif pada umumnya mengandung $\mathrm{O}-\mathrm{H}, \mathrm{C}=\mathrm{O}, \mathrm{C}=\mathrm{C}$ aromatik, dan gugus $\mathrm{C}$ $\mathrm{H}$, yang dijadikan gugus aktif untuk menyerap absorbat. Dari hasil terlihat bahwa sebagian besar puncak tidak mengalami pergeseran yang Nampak. Hal ini menunjukan adsorpsi secara fisika. Sedangkan terjadi penurunan dengan pergesaran bilangan gelombang menunjukan adsorpsi secara kimia. (Astuti dan Bayu, 2015)

\section{Aplikasi Karbon Aktif Kayu ulin Dalam Menyisihkan Cr pada Limbah Sasirangan}

Hasil karakteristik limbah cair sasirangan yang berada di Banjarmasin kandungan logam $\mathrm{Cr}$ sebesar 2,274 mg/L telah melebihi baku mutu menurut peraturan Gubernur Kalimantan Selatan No. 36 tahun 2008. Pengolahan limbah sasirangan dapat dilakukan dengan cara yang sederhana dengan 
menggunakan karbon aktif kayu ulin dan dapat menurunkan kandungan logam berat Cr yang terdapat di dalam limbah cair sasirangan. Setelah limbah sasirangan di adsorpsi menggunakan karbon aktif kayu ulin logam berat $\mathrm{Cr}$ yang berada di limbah sasirangan mengalami penurunan sebesar 0,7958 $\mathrm{mg} / \mathrm{L}$. Ini menunjukkan bahwa karbon aktif kayu ulin mampu menurunkan kandungan logam $\mathrm{Cr}$ yang ada pada limbah sasirangan sebesar 65\%. Berdasarkan kapasitas dalam penyisahan Cr pada limbah cair sasirangan, didapat hasil sebagai berikut:

Tabel 3 Kapasitas penyisihan Cr pada limbah sasirangan

\begin{tabular}{cccccc}
\hline No & $\begin{array}{c}\text { Kadar Cr } \\
\text { Awal } \\
(\mathbf{m g} / \mathbf{L})\end{array}$ & $\begin{array}{c}\text { Cr } \\
\text { Akhir } \\
(\mathbf{m g} / \mathbf{L})\end{array}$ & Dosis (gr) & Penyisihan & Sumber \\
\hline 1 & 12,4 & 0,15 & 2 & 6,125 & Lestari, (2016) \\
2 & 18,12 & 8,81 & 6 & 1,5533 & Safriansyah, (2014) \\
\hline
\end{tabular}

Dari Tabel 3 diatas menurut penelitian Lestari (2016), menyatakan bahwa arang aktif sekam padi mampu mengadsorpsi kandungan logam $\mathrm{Cr}$ pada limbah cair sasirangan dengan kadar $\mathrm{Cr}$ awal sebesar 12,4 mg/L setelah dilakukan adsorpsi efesiensi logam $\mathrm{Cr}$ pada limbah cair sasirangan mengalami penurunan menjadi $0,15 \mathrm{mg} / \mathrm{L}$. hal ini menunjukan bahwa arang aktif sekam padi memiliki kandungan karbon yang cukup tinggi, sehingga mampu menurunkan Cr yang sangat besar pada limbah sasirangan hingga 87,90\%. Sedangkan menurut penelitian Safriansyah (2014), absorben gambut lapis tengah dengan konsentrasi kandungan $\mathrm{Cr}$ awal sebesar 18,12 mg/L dan setelah dikontak menggunakan adsorben kandungan $\mathrm{Cr}$ pada limbah sasirangan mengalami penurunan sebesar 8,81 mg/L. absorben gambut mampu menyisihkan kandungan Cr pada limbah sasirangan sebesar 51,37\% .

Perbedaan penyerapan $\mathrm{Cr}$ pada limbah sasirangan dikarenakan dari penggunaaan bahan baku yang berbeda. Jenis bahan baku sangat berpengaruh besar dalam penyerapan logam. Sehingga bahan baku yang berbeda jenis sangat mempengaruh dalam proses penyerapan di limbah sasirangan itu sendiri.

\section{KESIMPULAN}

Variasi waktu perendaman karbon aktif serbuk kayu ulin dengan aktivasi kimia menggunakan $\mathrm{KOH}$ diperoleh waktu terbaik selama 24 jam dan kondisi operasi terbaik pada 3M. Sedangkan untuk karbon aktif serbuk kayu ulin dapat menurunkan logam $\mathrm{Cr}$ dalam sampel limbah cair sasirangan.

\section{DAFTAR PUSTAKA}

Abdurachman. 2012. Tanaman Ulin (Eusideroxylon Zwageri T. \& B) Pada Umur 8,5 Tahun Di Arboretum Balai Besar Penelitian Dipterokarpa Samarinda.

Astuti, W dan Bayu K. 2015. Adsorpsi Pb2+ Dalam Limbah Cair Artifisial Menggunakan Sistem Adsorpsi Kolom Dengan Bahan Isian Abu Layang Batubara Serbuk dan Granular. Universitas Negeri Semarang.

Buyung Safriansyah. 2014. Pembuatan Absorben Gambut Dari Kedalaman Yang Berbeda dan Aplikasinya Untuk Menurunkan Cr Total Dalam Limbah Cair Sasirangan. Universitas Lambung Mangkurat. Banjarbaru.

Dwi Setiawan, Cahya. 2014. Pembuatan Arang Aktif Kayu Ulin Dengan Aktivasi Kimia Menggunakan KOH Dan AplikasinyaUntuk Menurunkan Bahan Organik Alami (BOA) Pada Air Sungai. Skripsi. Fakultas Teknik. Universitas Lambung Mangkurat. Banjarbaru. Hlm 40 
Edema, M. O., Sichamba, V \& Ntengwe, F. W. (2012). Solid Waste Management-Case Study Of Ndola, Zambia. IJPAES. Vol 2. No 3. Juli-September

Fakhrizal. Rizki Fauzi. Yuli Ristianingsih. 2016. Reduksi Logam Cr6+ Total Limbah Cair Sasirangan Menggunakan Metode Adsorpsi Dengan Ekstrak Pektin Dari Kulit Pisang. Proseding Seminar Nasional Industri Kimia dan Sumber Daya Alam ISBN 978-60270195-1-5 Program Studi Teknik Kimia Fakultas Teknik Universitas Lambung Mangkurat 166

Herbest, W \& Hunger, K. 2004. INDUSTRIAL ORGANIC pigments. wiley-VCH Verleg GmbH \& Co. KgaA. Weinheim.

Imawati, Anita dan Adhitiyawarman. 2015. Kapasitas Adsorpsi Maksimum Ion Pb (II) oleh Arang Aktif Ampas Kopi Teraktivasi $\mathrm{HCl}$ dan $\mathrm{H}_{3} \mathrm{PO}_{4}$. JKK. Volume 4 (2), hal : 50-61. Fakultas MIPA. Tanjungpura.

Jauhari, A. Noor Mirad sari. 2007. Pengaruh Variasi penambahan Ragi dan Lamanya Waktu Fermentasi Terhadap Hasil Fermentasi Etanol Dari Serbuk Gergaji Kayu Ulin. Fakultas Kehutanan. UNLAM, Banjarbaru.

Kartohardjono, Sutrasno. M. Ali Lukman dan G.P. manik. 2008.Penentuan Kulit Batang Jambu Biji (Psidium guajava) Untuk adsorpsi $\mathrm{Cr}^{6+}$ dari larutan http://repository.ui.ac.id/contents/koleksi/11/92eb8f9ca6cc7f96543eec13c680c68b6d9d8

5aa.pdf (akses tanggal 20 Desember 2016)

Kusuma, Gita Ardia. 2009. Pendugaan Potensi Karbon Di Atas Permukaan Tanah Pada Tegakan Hutan Hujan Tropis Bekas Tebangan (Loa) 1983 (Studi Kasus Iuphhk Pt. Suka Jaya Makmur). Institut Pertanian Bogor.

Langenati, R , Rachmad M. M. , Deni .M , Bangun .W, Ridwan. (2012). Pengaruh Jenis Adsorben dan Konsentrasi Uranium Terhadap Pemungutan Uranium Dari Larutan Uranil Nitrat. Jurnal Pusat Teknologi Bahan Bakar Nuklir. Sekolah Tinggi Teknologi Nuklir-BATAN. Jogyakarta.

Lestaluhu, K.H. (2015). Kefektifan Ampas Sagu Sebagai Biosorben Untuk Mengadsorpsi Ion Timbal (PB). Jurnal Jurusan Teknik Lingkungan. Fakultas Teknik Sipil Universitas Hasanuddin. Makassar.

Lestari, Dwi Indah. 2016. Skripsi : Pengaruh Variasi Ukuran Arang Aktif Sekam Padi pada Proses Adsorpsi Cr Total pada Limbah Cair Sasirangan dengan Sistem Batch. Universitas Lambung Mangkurat.

Mizwar, A. 2013. Penyisihan warna pada limbah cair sasirangan dengan adsorpsi zeolite dalam fixed-bad column. Banjarbaru, Indonesia

Murniati. Sukaesih Pradjadinata. (2014). Pengelolaan Dan Konservasi Jenis Ulin (Eusideroxylon zwageri Teijsm. \& Binn.) di Indonesia. Pusat Litbang Konservasi dan Rehabilitasi, Bogor.

Oktaviani, A. 2014. Pembuatan Arang Aktif Kayu Ulin dengan Aktivasi Kimia Menggunakan $\mathrm{H}_{2} \mathrm{SO}_{4}$ dan Aplikasinya Untuk Menurunkan Bahan Organik Alami (BOA) Pada Air Sungai. Skripsi Fakultas Teknik. Universitas Lambung Mangkurat.

Pradista, D.S. (2016). Studi Adsorpsi Dua Tahap Krom Heksavalen $\left(\mathrm{Cr}^{6+}\right)$ Terhadap Adsorben Gambut Dengan Sistem Batch. Laporan Penelitian Fakultas Teknik UNLAM.Banjarbaru.

Safriansyah, B. (2014). Pembuatan Adsorben Gambut Dari Kedalaman Yang Berbeda Dan Aplikasinya Untuk Menurunkan Cr Total Dalam Limbah Cair Sasirangan. Laporan penelitian Fakultas Teknik UNLAM Banjarbaru.

Santoso. (2012). Preparasi dan Aplikasi Komposit Hidroksiapatit/Kitosan Sebagai Adsorben Logam Berat. Fakultas Teknik Departemen Teknik Kimia. Universitas Indonesia. Depok 
Saputro, Mugiyono. 2010. Pembuatan Karbon Aktif Dari Kulit Kacang Tanah (Arachis hypogaea) dengan activator asam sulfat. Teknik Kimia. Universitas Diponegoro. Semarang

Sembiring, M. T., dan Tuti Sarma Sinaga 2003. Arang Aktif(Pengenalan dan Proses Pembuatannya). Medan: Universitas Sumatera Utara.

Siti Salamah. 2008. Pembuatan Karbon Aktif Dari Kulit Buah Mahoni Dengan Perlakuan Perendaman Dalam Larutan KOH. Universitas Ahmad Dahlan. Yogyakarta.

Sitorus, D. Oktavia. 2014. Arang Aktif Serbuk Gergaji Kayu Ulin dan Serabut Kelapa. Politeknik Sriwijaya. Palembang.

Untung Santoso, 2014. Pengelolaan Limbah Cair Sasirangan Melalui Kombinasi Metode Filtrasi dan Fitoremediasi Sistem Lahan Basah Buatan Menggunakan Tumbuhan Air yang Berbeda. Tesis Pascasarjana Universitas Lambung Mangkurat. Banjarbaru.

Utami, U.B. L,. 2008. Pemanfaatan Karbon Aktif Limbah Kayu Ulin sebagai Adsorben Limbah Cair Sasirangan. Laporan Penelitian Fakultas MIPA, Universitas Lambung Mangkurat. Banjarbaru.

Widihati, I.A.G. (2008). Adsorpsi Anion Cr(VI) oleh Batu Pasir Teraktivasi Asam dan Tersalut Fe2O3. Jurnal Kimia, 2(1): 25-30.

Wang L, Guo Y, Rong C, MaX, Qu Y, Wang Z. 2011. High surface area porous carbons prepared from hydrochars by phosphoric acid activation. Bioresource Technology. 102: 19471950.

Widyasari, N. 2014. Pembuatan Arang Aktif Kayu Ulin dengan Aktivasi Fisika dan Aplikasinya Untuk Menurunkan Bahan Organik Alami (BOA) Pada Air Sungai. Skripsi Fakultas Teknik. Universitas Lambung Mangkurat. Banjarbaru 